OPEN ACCESS

Edited by:

Guilherme Mariz de Oliveira Barra, Federal University of Santa

Catarina, Brazil

Reviewed by: Johnny De Nardi Martins, Federal University of Santa

Catarina, Brazi

Walter Caseri,

ETH Zürich, Switzerland

${ }^{*}$ Correspondence: Boris Lakard

boris.lakard@univ-fcomte.fr

Specialty section:

This article was submitted to Polymeric and Composite Materials,

a section of the journal

Frontiers in Materials

Received: 19 March 2019 Accepted: 20 May 2019

Published: 06 June 2019

Citation:

Contal E, Sougueh CM, Lakard S, Et Taouil A, Magnenet $C$ and Lakard $B$ (2019) Investigation of Polycarbazoles

Thin Films Prepared by

Electrochemical Oxidation of

Synthesized Carbazole Derivatives.

Front. Mater. 6:131.

doi: 10.3389/fmats.2019.00131

\section{Investigation of Polycarbazoles Thin Films Prepared by Electrochemical Oxidation of Synthesized Carbazole Derivatives}

\author{
Emmanuel Contal, Charmaké Moussa Sougueh, Sophie Lakard, Abdeslam Et Taouil, \\ Claire Magnenet and Boris Lakard*
}

Institute UTINAM, UMR CNRS 6213, University of Bourgogne Franche-Comté, Besançon, France

Polycarbazole and its derivatives have advantages of good environmental stability, electrochromic properties and photoconductivity which have attracted considerable attention because of their potential industrial applications in electroluminescent applications, rechargeable batteries, and light emitting diodes. They have the possibility of different position substitution (carbon $\mathrm{C}_{3}-\mathrm{C}_{3}$ ' or $\mathrm{N}$ ) that lead to different electropolymerization behaviors. However, the $\mathrm{N}$ position facilitates the grafting of various derivatives of interest and permits not to modify so much the radical cation formation during electropolymerization. In this paper, carbazole and its derivatives were electrochemically oxidized in acetonitrile solutions leading to the formation of thin polymer films. The morphological features and electrochemical properties of the as-formed polymer films were investigated in detail. Thanks to these experiments, the influence of the substitution on the properties of the polymer films was evidenced and discussed. In addition, fast electrochemistry experiments were carried out on platinum microelectrodes within $50-1,000 \mathrm{~V} / \mathrm{s}$ scan speed range. Reactivity of carbazole derivatives radical cations and dimers was investigated through these experiments. Thermodynamic and kinetic information (e.g., redox standard potential, heterogeneous, and dimerization rate constants) was extracted after coupling with electrochemical simulations.

Keywords: electrochemistry, conducting polymers, carbazoles, reactivity, functionalization

\section{INTRODUCTION}

The discovery of organic conducting polymers in Shirakawa's laboratory in the early 1970s and the demonstration by MacDiarmid et al. of the semiconducting properties of polyacetylene (Shirakawa et al., 1977) paved the way for an intense research activity on these materials to exploit these conducting properties. Thus, over the last decades, other organic semiconducting polymers like polypyrrole, polyaniline, polythiophene, or polycarbazole have been gaining increasing interest, owing to their interesting physicochemical properties, for many different applications including flexible electronics (Savagatrup et al., 2014; Lee et al., 2018), optoelectronics (Ouyang et al., 2005; Akiyama et al., 2009; Cai et al., 2017), and energy storage devices (Mali et al., 2015; Bryan et al., 2016; Kausar, 2017). 
Various methods have been used in the past for growing such conducting polymers including chemical oxidation (Huang et al., 2012), plasma polymerization (Yaguee et al., 2008), LangmuirBlodgett technique (Park et al., 2003), or electrochemistry (Fonseca et al., 2017). Among these methods, electrochemical deposition is the most convenient and reliable method for growing conducting polymer thin films with controlled properties. Indeed, many physico-chemical properties [including conductivity (Patois et al., 2010), morphology and roughness (Patois et al., 2011) or wettability (Darmanin and Guittard, 2014)] of electrodeposited polymer films can be easily tuned by varying electrochemical conditions [such as solvent (Viau et al., 2014; Wojcik and Grzeszczuk, 2015), electrodeposition potential (Chmielewski et al., 2010), nature of the counter-anions (Atobe et al., 2006), temperature (Wojcik and Grzeszczuk, 2015), or pH (Peng et al., 2009)].

Carbazole is one of the aromatic heterocyclic organic compounds that could lead to the formation of a conducting polymer film by oxidation. Resulting carbazole-based conjugated polymer films can be used as components of sensors (Joshi et al., 2014; Vedarajan et al., 2014), batteries (Saraswathi et al., 1999), OLED (Grigalevicius et al., 2011; Srivastava and Chakrabarti, 2015), or electrochromic devices (Hu et al., 2013; Hsiao and Lin, 2016), mainly because of their electron-donating nature, high photoconductivity and strong fluorescence.

To tune properties of conducting polymers, it is possible to modify heterocyclic monomers by incorporation of functional groups with specific properties. Indeed, carbazole monomers have the possibility of substitution at N-position. Such chemical modification provides the opportunity to improve both the solubility and functionality of the resulting polymer. In addition, flexible side chains can cause steric hindrance and thereby provide a means to control the effective conjugation length.

Thus, chemical modifications to the carbazole monomers leading to $\mathrm{N}$-substituted derivatives have already been done (Ambrose and Nelson, 1968; Ambrose et al., 1975; Chevrot et al., 1996; Wei et al., 2006). In particular, anodic electrochemical oxidation of carbazole and its $\mathrm{N}$-substituted derivatives $(\mathrm{N}$ methylcarbazole, $\mathrm{N}$-ethylcarbazole, and $\mathrm{N}$-isopropylcarbazole) were first studied by Ambrose and Nelson (1968); Ambrose et al. (1975). They investigated the reactivity of cation radicals formed from these substituted carbazoles using electrochemical and spectroscopic techniques and reported that their electrochemical oxidation leads to only 3,3'-bicarbazyls and not to $9,9^{\prime}$ bicarbazyls due to the fact that the 9-position is already occupied. The optical and electronic properties of undoped and doped electrodeposited poly(N-ethylcarbazole) thin layers were also characterized by Chevrot et al. (1996). In another study, Wei et al. have prepared high quality polymer films by anodic electrooxidation of carbazole and its alkyl derivatives N-octylcarbazole, $\mathrm{N}$-(6-bromohexyl)carbazole, and 1,6-bis(carbazolyl)hexane in boron trifluoride diethyl etherate (BFEE) or mixed electrolytes $\mathrm{BFEE}+\mathrm{CHCl}_{3}$ (Wei et al., 2006). However, among the various carbazole incorporated polymers, a central place is reserved to $\mathrm{N}$-vinylcarbazole because it is easily synthesized and soluble in common organic solvents. Thus, the polymerization of $\mathrm{N}$-vinylcarbazole in ethylenedichloride, acetone, benzene, and dioxane with cupric nitrate, ferric nitrate, and ceric ammonium nitrate catalysts was studied by Sarac and Bardavit (2004). Similarly, poly(N-vinylcarbazole) films were synthesized by electrochemical oxidation of $\mathrm{N}$-vinylcarbazole in acetonitrile (Reyna-Gonzalez et al., 2006; Reyna-González et al., 2009). In this work, Reyna-Gonzalez et al. evidenced that modifying the acidity of the electrolyte leads to the deposition of polymer films with various properties in terms of chemical structure, morphology, conductivity, and optical properties. Such poly-(Nvinylcarbazole) films have been used as solar cells materials ( $\mathrm{Su}$ et al., 2017), as sensing materials (Papez and Josowicz, 1994), or as light-emitting diode materials (Li et al., 2010; Cai et al., 2011).

Taking into account this literature, the present study aimed at preparing various $\mathrm{N}$-substituted polycarbazole films by electrochemical oxidation using optimum electrodeposition conditions (in terms of solvent, supporting salt and monomer concentration) deduced from the study of carbazole electropolymerization. Then, the reactivity of carbazole derivatives radical cations and dimers was investigated through fast electrochemistry experiments to determine the influence of the substitution. Electrochemical properties and morphology of the various substituted polycarbazole films were also studied and compared.

\section{MATERIALS AND METHODS}

\section{Reagents}

Carbazole $(\mathrm{Cz}, 95 \%)$ and vinylcarbazole $(\mathrm{CzV}, 98 \%)$ were purchased from Sigma Aldrich. 9-ethyl-9H-carbazole (Cz1Me, 97\%) was from TCI. Acetone (99.98\%) and dimethylformamide (99.8\%) were from Fisher Chemical. Lithium perchlorate, tetraethylammonium p-toluenesulfonate (TS), tetrabutylammonium hexafluorophosphate (TH), and tetrabutylammonium tetrafluoroborate (TBAB) were from Sigma-Aldrich.

All other chemical reagents used to prepare monomers were purchased from TCI or Sigma Aldrich and used as received unless otherwise stated. ${ }^{1} \mathrm{H}$ and ${ }^{13} \mathrm{C}$ NMR spectra were recorded on a Bruker AC 400 spectrometer. RMN spectra are given in Supplementary Files.

\section{Synthesis}

\section{General Procedure to Alkylcarbazoles}

$\mathrm{KOH}$ ( $2.50 \mathrm{~g}, 1.5 \mathrm{eq})$ and bromoalkane (45 mmol, $1.5 \mathrm{eq})$ were added at room temperature to a stirred solution of carbazole $(5.00 \mathrm{~g}, 30 \mathrm{mmol})$ in acetone $(30 \mathrm{~mL})$. Then the reaction mixture was refluxed for $24 \mathrm{~h}$. After cooling, water was added $(30 \mathrm{~mL})$ and the reaction mixture was neutralized with $0.1 \mathrm{M} \mathrm{HCl}$ solution. The solution was extracted with diethylether $\left(3^{*} 50 \mathrm{~mL}\right)$. The combined organic layers were dried over sodium sulfate, filtered, and concentrated by rotary evaporation. The crude product was purified by chromatography (Dichloromethane/Cyclohexane 1/1 as eluent) to give the final compound.

\section{9-butyl-9H-carbazole (Cz3Me)}

According to the general procedure, 9-butylcarbazole was obtained as a white solid (5.45 g, 81\%). ${ }^{1} \mathrm{H}$ NMR $(400 \mathrm{MHz}$, 
$\left.\mathrm{CDCl}_{3}\right): \delta(\mathrm{ppm}) 8.12(\mathrm{~d}, 2 \mathrm{H}, J=7.6 \mathrm{~Hz}), 7.46(\mathrm{~d}, 2 \mathrm{H}, J=$ $8.0 \mathrm{~Hz}), 7.24(\mathrm{~d}, 2 \mathrm{H}, J=6.4 \mathrm{~Hz}), 4.30(\mathrm{t}, 2 \mathrm{H}, J=7.2 \mathrm{~Hz})$, 1.85 (quint, $2 \mathrm{H}, J=7.2 \mathrm{~Hz}), 1.40(\mathrm{td}, 2 \mathrm{H}, J=7.6 \mathrm{~Hz}, J=$ $7.6 \mathrm{~Hz}), 0.95(\mathrm{t}, 2 \mathrm{H}, J=7.2 \mathrm{~Hz}) .{ }^{13} \mathrm{C} \mathrm{NMR}\left(100 \mathrm{MHz}, \mathrm{CDCl}_{3}\right)$ : $\delta(\mathrm{ppm}) 140.4,125.5,122.7,120.3,118.6,108.6,42.8,31.1$, 20.5, 13.9. Analyses were consistent to already published data (Petrov et al., 2013).

\section{9-hexyl-9H-carbazole (Cz5Me)}

According to the general procedure, 9-hexylcarbazole was obtained as a white solid (6.30 g, 84\%). ${ }^{1} \mathrm{H}$ NMR $(400 \mathrm{MHz}$, $\left.\mathrm{CDCl}_{3}\right): \delta(\mathrm{ppm}) 8.07(\mathrm{~d}, 2 \mathrm{H}, J=7.6 \mathrm{~Hz}), 7.43(\mathrm{~m}, 2 \mathrm{H}), 7.35$ $(\mathrm{d}, 2 \mathrm{H}, J=8 \mathrm{~Hz}), 7.20(\mathrm{t}, 2 \mathrm{H}, J=7.2 \mathrm{~Hz}), 4.21(\mathrm{t}, 2 \mathrm{H}, J=$ $7.2 \mathrm{~Hz}$ ), 1.80 (quint, $2 \mathrm{H}, J=7.2 \mathrm{~Hz}), 1.35-1.21(\mathrm{~m}, 6 \mathrm{H}), 0.85$ $(\mathrm{t}, 2 \mathrm{H}, J=7.2 \mathrm{~Hz}) .{ }^{13} \mathrm{C} \mathrm{NMR}\left(100 \mathrm{MHz}, \mathrm{CDCl}_{3}\right): \delta(\mathrm{ppm})$ $140.4,125,5 ; 122,8 ; 120,3 ; 118,6 ; 108,6 ; 43,0 ; 31,6 ; 28,9 ; 26,9$; 22,$5 ; 14,0$. Analyses were consistent to already published data (Petrov et al., 2013).

\section{9-octyl-9H-carbazole (Cz7Me)}

According to the general procedure, 9-octylcarbazole was obtained as a colorless oil $(7.95 \mathrm{~g}, 94 \%) .{ }^{1} \mathrm{H}$ NMR $(400 \mathrm{MHz}$, $\left.\mathrm{CDCl}_{3}\right): \delta(\mathrm{ppm}) 8.10(\mathrm{~d}, 2 \mathrm{H}, J=7.6 \mathrm{~Hz}), 7.47(\mathrm{~m}, 2 \mathrm{H}), 7.42(\mathrm{~d}$, $2 \mathrm{H}, J=8.0 \mathrm{~Hz}), 7.23(\mathrm{td}, 2 \mathrm{H}, J=7.2 \mathrm{~Hz}, J=1.2 \mathrm{~Hz}), 4.30(\mathrm{t}, 2 \mathrm{H}, J$ $=7.2 \mathrm{~Hz}$ ), 1.88 (quint, $2 \mathrm{H}, J=7.2 \mathrm{~Hz}), 1.42-1.20(\mathrm{~m}, 10 \mathrm{H}), 0.87$ $(\mathrm{t}, 2 \mathrm{H}, J=7.2 \mathrm{~Hz}) .{ }^{13} \mathrm{C} \mathrm{NMR}\left(100 \mathrm{MHz}, \mathrm{CDCl}_{3}\right): \delta(\mathrm{ppm}) 140.4$, $125.6,122.8,120.3,118.7,108.6,43.1,31.8,29.4,29.2,29.0,27.3$, 22.6, 14.0. Analyses were consistent to already published data (Sathiyan and Sakthivel, 1993).

\section{$\mathrm{N}$-((Methoxycarbonyl)methyl)carbazole (CzE)}

Carbazole $(4.2 \mathrm{~g}, 30 \mathrm{mmol})$ was added at $0^{\circ} \mathrm{C}$ to a suspension of $\mathrm{NaH}(60 \%$ in oil, $2.0 \mathrm{~g}, 2$ eq) in a dry THF/DMSO solution $(80 / 40 \mathrm{~mL})$. The mixture was stirred for $1 \mathrm{~h}$ and methyl bromoacetate was added $(5.8 \mathrm{~g}, 1.5 \mathrm{eq})$. The reaction mixture was stirred overnight then quenched with water. The solution was extracted with diethylether $\left(3^{*} 100 \mathrm{~mL}\right)$. The combined organic layers were dried over sodium sulfate, filtered and concentrated by rotary evaporation. The crude product was purified by chromatography (Dichloromethane/Cyclohexane $1 / 1$ as eluent) to yield a white solid (4.37 g, 73\%). ${ }^{1} \mathrm{H}$ NMR (400 $\mathrm{MHz}, \mathrm{CDCl}_{3}$ ): $\delta(\mathrm{ppm}) 8.02(\mathrm{~d}, 2 \mathrm{H}, J=7.6 \mathrm{~Hz}), 7.40(\mathrm{t}, 2 \mathrm{H}, J=8.0 \mathrm{~Hz})$, $7.20(\mathrm{~m}, 4 \mathrm{H}), 4.92(\mathrm{~s}, 2 \mathrm{H}), 3.63(\mathrm{~s}, 3 \mathrm{H}) .{ }^{13} \mathrm{C} \mathrm{NMR}(100 \mathrm{MHz}$, $\left.\mathrm{CDCl}_{3}\right): \delta$ (ppm) 169.0, 140.5, 126.0, 123.2, 120.5, 119.7, 108.3, $52.5,44.6$. Analyses were consistent to already published data (Conn et al., 1993).

\section{2-(9H-Carbazol-9-yl)acetic acid (CzA)}

$\mathrm{N}$-((Methoxycarbonyl)methyl)carbazole $(1.08 \mathrm{~g}, 4.3 \mathrm{mmol})$ was dissolved in a $\mathrm{THF} / \mathrm{H}_{2} \mathrm{O}$ solution $(5 / 5 \mathrm{~mL}) . \mathrm{KOH}(0.8 \mathrm{~g}, 3 \mathrm{eq})$ was added and the solution was stirred at room temperature overnight. Then THF was removed by evapory rotation and aqueous solution was acidified to $\mathrm{pH}=1$ with $1 \mathrm{M} \mathrm{HCl}$ solution. The precipitated compound was filtered, washed with cold water and dried under vacuum to yield a white solid (0.6 g, $56 \%) .{ }^{1} \mathrm{H}$ NMR (400 MHz, $\left.\mathrm{CDCl}_{3}\right): \delta(\mathrm{ppm}) 8.02(\mathrm{~d}, 2 \mathrm{H}, J=7.6 \mathrm{~Hz}), 7.40$ $(\mathrm{t}, 2 \mathrm{H}, J=8.0 \mathrm{~Hz}), 7.20(\mathrm{~m}, 4 \mathrm{H}), 4.97(\mathrm{~s}, 2 \mathrm{H}) .{ }^{13} \mathrm{C}$ NMR $(100$ $\left.\mathrm{MHz}, \mathrm{CDCl}_{3}\right): \delta(\mathrm{ppm}) 173.1,140.4,126.1,123.3,120.6,119.9$,
108.2, 44.1. Analyses were consistent to already published data (Zhang et al., 2014).

\section{Electrochemistry}

\section{Electrodeposition of $\mathrm{Cz}$ and Its Derivatives}

First, electrochemistry was used to study the electrochemical oxidation of the monomers on a platinum wire (area: 0.785 $\mathrm{mm}^{2}$ ) using cyclic voltammetry technique (5 potential scans were done at $50 \mathrm{mV} / \mathrm{s}$ ). Then, after optimization of the electrolyte composition, polycarbazole films were prepared using chronoamperometry technique $(3 \mathrm{~min}$ of oxidation at the oxidation peak potential deduced from the corresponding cyclic voltammetry) on a Fluorine doped Tin Oxide (FTO) substrate $\left(\mathrm{R}=80 \mathrm{~V} / \mathrm{square}\right.$, area: $\left.1.5 \mathrm{~cm}^{2}\right)$, before being extensively characterized.

The electrochemical activity of polyCz was also estimated by doing a cyclic voltammetry at a Pt electrode coated with a PCz film in the same electrolyte but in the absence of monomer. This electrode was rinsed in acetonitrile between the cycling in the solutions with monomers and those without.

All these electrochemical experiments were carried out at room temperature, with a VersaSTAT MC potentiostat/galvanostat from Princeton Applied Research, in a single-compartment cell with a three electrode set-up. This set-up employed a Saturated Calomel Electrode (SCE) as reference electrode, a platinum sheet as counter-electrode, and either a platinum wire or a FTO substrate as working electrode.

\section{Fast Electrochemistry}

Fast electrochemistry experiments were carried out using an AUTOLAB PGSTAT30 potentiostat equipped with SCAN250 and ADC10M modules. A classical three-electrode cell was used with platinum microelectrode (diameter $246 \mu \mathrm{m}$ calibrated with ferrocene system) as working electrode, platinum wire as counter-electrode and $\mathrm{Ag} / \mathrm{AgCl}$ reference electrode. The solution contained $1.5 \mathrm{mM}$ of functionalized carbazole and $0.1 \mathrm{M}$ of $\mathrm{TBAB}$ in acetonitrile. Electrochemical simulations were realized with DigiElch Pro software.

\section{Characterization SEM Microscopy}

The surface morphology of the polycarbazole films was observed with a high-resolution Scanning Electron Microscope Quanta $450 \mathrm{~W}$ (from FEI) with an electron beam energy of $12.5 \mathrm{keV}$ and a working distance of $9 \mathrm{~mm}$. No metallization pre-treatment was needed since the samples were conductive.

\section{Profilometry}

Thickness and roughness of electrodeposited films were measured using a stylus-based mechanical probe profiler (AlphaStep IQ, from KLA Tencor). Both thickness and roughness were obtained by moving this stylus perpendicularly to the film on a scan length of $3,000 \mu \mathrm{m}$ at a scan speed of $50 \mu \mathrm{m} . \mathrm{s}^{-1}$. Five measurements were achieved at different positions for each film. 


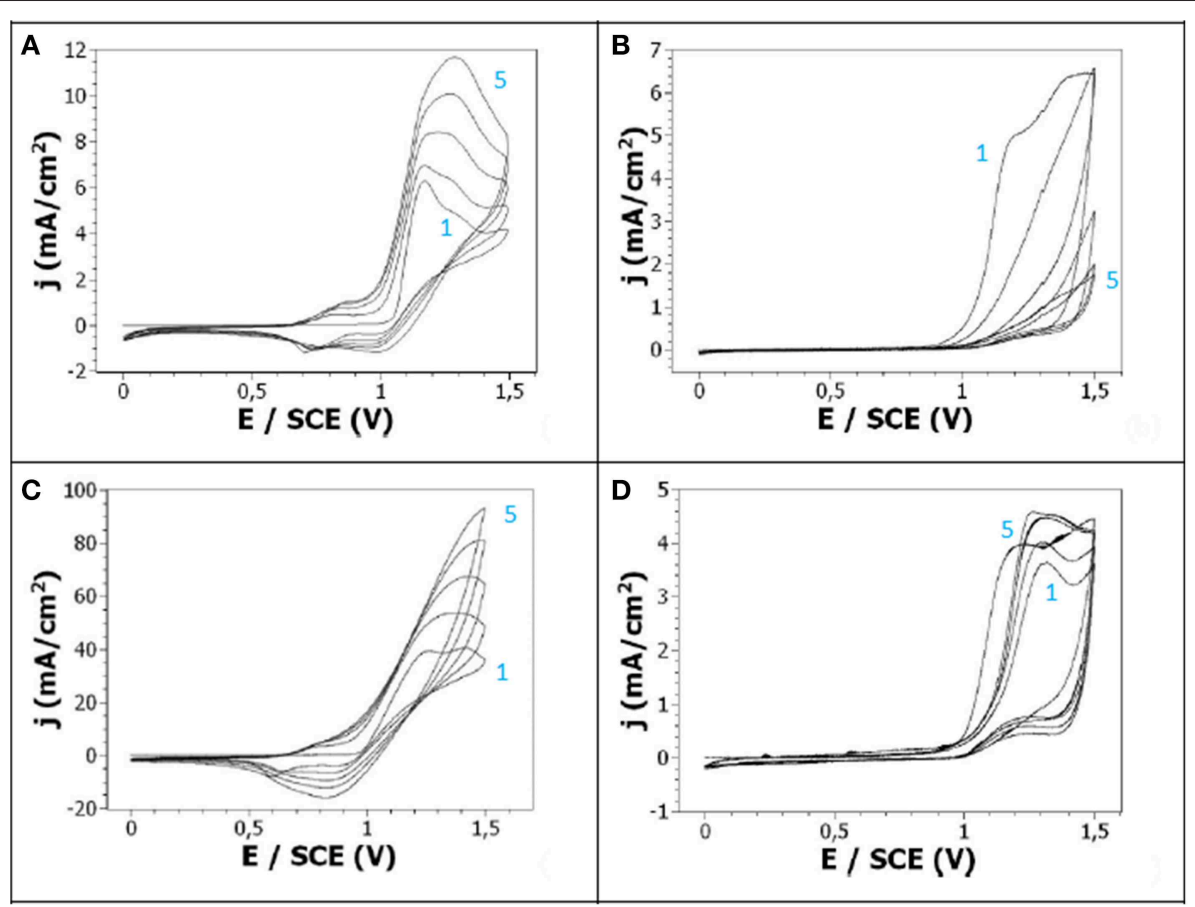

FIGURE 1 | Cyclic voltammetry at a Pt electrode of: (A) $10^{-2} \mathrm{M} \mathrm{Cz}+0.1 \mathrm{M} \mathrm{LiClO}_{4}$ in ACN, (B) $10^{-2} \mathrm{M} \mathrm{Cz}+0.1 \mathrm{M} \mathrm{LiClO}_{4}$ in DMF, (C) $10^{-1} \mathrm{M} \mathrm{Cz}+0.1 \mathrm{M} \mathrm{LiClO}$ in ACN, (D) $10^{-3} \mathrm{M} \mathrm{Cz}+0.1 \mathrm{M} \mathrm{LiClO}_{4}$ in ACN. Scan rate: $50 \mathrm{mV} / \mathrm{s}$.

\section{RESULTS}

\section{Electropolymerization of Carbazole at Pt Electrodes by Cyclic Voltammetry} Influence of the Solvent and Carbazole Concentration The oxidation of $10^{-2} \mathrm{M}$ carbazole was performed by cyclic voltammetry (CV) at Pt electrodes in $0.1 \mathrm{M} \mathrm{LiClO}_{4}$ in acetonitrile (ACN) or dimethylformamide (DMF) solutions (Figure 1). The onset oxidation potentials of carbazole, leading to $\mathrm{Cz}$ radical cations, in $\mathrm{LiClO}_{4} / \mathrm{ACN}$ and $\mathrm{LiClO}_{4} / \mathrm{DMF}$, appears at 1.05 and $0.95 \mathrm{~V} / \mathrm{SCE}$, respectively. The redox process of polycarbazole is observed in ACN since a polyCz oxidation peak and a polyCz reduction peak are clearly distinguishable at +0.8 and +0.7 V/SCE, respectively. After the first cycle, both $\mathrm{Cz}$, and polyCz oxidation potential peak intensity increases and potentials shift toward higher values. The gradual increase of the reduction peak intensity with repeated scans indicates the progressive deposition of the polymer on the Pt surface. Moreover, the $\mathrm{i}_{\mathrm{a}} / \mathrm{i}_{\mathrm{c}}$ ratio of the redox polyCz peaks is close to 1 , indicating a good reversibility of the redox process.

This electrochemical behavior is consistent with the electropolymerization mechanism previously reported (Ambrose and Nelson, 1968). This mechanism begins with the oxidation of carbazole monomers leading to the formation of cation radicals in a one electron process. These cation radicals couple with each other or with a parent molecule leading to 3,3'-bicarbazyls. After that, the oxidation of the oligomers takes place leading progressively to the formation of a polycarbazole film at the electrode surface.
On the contrary, the redox process was not distinguishable when the cyclic voltammetry was performed in DMF, and the intensity of the $\mathrm{Cz}$ oxidation peak decreased upon repeated scans, both indicating that this solvent is less appropriate for this reaction than $\mathrm{ACN}$. In addition, the film obtained by oxidation of $\mathrm{Cz}$ in DMF is very thin and copper-colored to the eye, contrary to the one obtained in $\mathrm{ACN}$ which is thicker and green-colored (Figure 2). This is in line with other studies which evidenced that acetonitrile was a better solvent than propylene carbonate and dichloromethane for the electropolymerization of $\mathrm{Cz}$ (Sarac et al., 2006).

The influence of the monomer concentration was then studied by comparing the cyclic voltammetry obtained from $10^{-2} \mathrm{M} \mathrm{Cz}$ in an acetonitrile solution (using $0.1 \mathrm{M} \mathrm{LiClO}_{4}$ as supporting electrolyte) with the ones obtained from similar solutions containing $\mathrm{Cz}$ concentrated at $10^{-3}$ and $10^{-1} \mathrm{M}$ (Figures 1C,D). Thus, the cyclic voltammetry obtained with $10^{-1} \mathrm{M} \mathrm{Cz}$ shows great similarities with the one obtained at $10^{-2} \mathrm{M}$, in particular a $\mathrm{Cz}$ oxidation peak beginning at $+1.0 \mathrm{~V} / \mathrm{SCE}$ whose intensity increases with repeated scans and potential shifts toward higher values, and two reversible redox peaks corresponding to the oxidation and reduction of the polyCz. On another side, the $\mathrm{Cz}$ oxidation peak was narrower at $10^{-2} \mathrm{M}$ and its intensity was 10 times lower, both due to the lower monomer concentration. After this electrochemical oxidation, a thick green-colored film was obtained (Figure 2). On the contrary, the cyclic voltammetry obtained with $10^{-3} \mathrm{M} \mathrm{Cz}$ was very different from the ones obtained at $10^{-1}$ and $10^{-2} \mathrm{M}$ since there was no increase with repeated scans of the $\mathrm{Cz}$ oxidation peak appearing at $+1.0 \mathrm{~V} / \mathrm{SCE}$ 

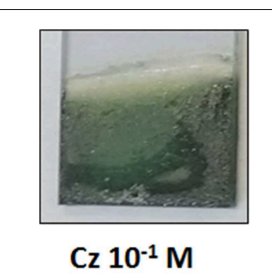

$+\mathrm{LiClO}_{4}$ $+\mathrm{ACN}$

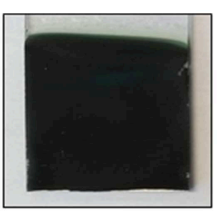

$\mathrm{Cz} 10^{-2} \mathrm{M}$

$+\mathrm{LiClO}_{4}$

$+\mathrm{ACN}$

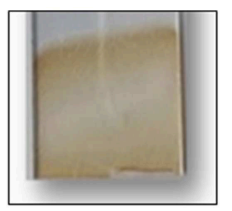

$\mathrm{Cz} 10^{-3} \mathrm{M}$

$+\mathrm{LiClO}_{4}$

$+\mathrm{ACN}$

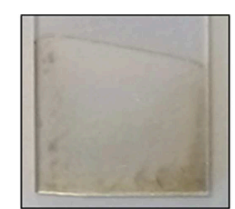

$\mathrm{Cz} 10^{-2} \mathrm{M}$

$+\mathrm{LiClO}_{4}$

$+\mathrm{DMF}$

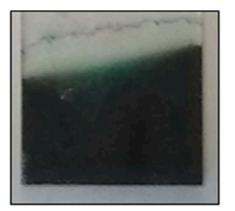

$\mathrm{Cz} 10^{-2} \mathrm{M}$

+ TBAB

$+\mathrm{ACN}$

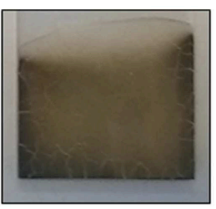

$\mathrm{Cz} 10^{-2} \mathrm{M}$

$+\mathrm{TS}$

$+\mathrm{ACN}$

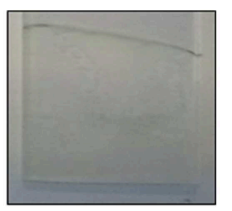

$\mathrm{Cz} 10^{-2} \mathrm{M}$

$+\mathrm{TH}$

$+\mathrm{ACN}$

FIGURE 2 | Photographs of samples obtained by oxidation of carbazole at different concentrations and in electrolytes containing different solvents and supporting salts.

and no distinguishable redox peaks. Moreover, only a very thin pale yellow film is formed (Figure 2).

It can be deduced from these experiments that the best solvent for studying $\mathrm{Cz}$ electropolymerization is acetonitrile and the optimized monomer concentration is $10^{-2} \mathrm{M}$ rather than $10^{-1}$ $\mathrm{M}$ since the $\mathrm{PCz}$ film obtained with $10^{-2} \mathrm{M} \mathrm{Cz}$ is more adherent and more uniform (Figure 2). In addition, the solubility of $\mathrm{Cz}$ into acetonitrile is more difficult in $0.1 \mathrm{M} \mathrm{Cz}$.

\section{Influence of the Supporting Salt}

To determine the influence of the nature of the supporting salt, in particular the influence of its anions acting as dopants, on the electrochemical oxidation of carbazole, cyclic voltammograms were performed from an acetonitrile solution containing carbazole and one of the following salts: lithium perchlorate $\left(\mathrm{LiClO}_{4}\right)$, tetrabutylammonium tetrafluoroborate (TBAB), tetraethylammonium p-toluenesulfonate (TS), or tetrabutylammonium hexafluorophosphate (TH). These salts were chosen because they have different sizes, contain different anions, provide a good conductivity to the electrolyte and facilitate the dissolution of monomers in the electrolyte.

The cyclic voltammogramm obtained with TBAB salt (Figure 3B) presented similarities with the one previously obtained with $\mathrm{LiClO}_{4}$ (Figure 3A). Indeed, the onset potentials of $\mathrm{Cz}$ in TBAB/ACN is located at $+1.1 \mathrm{~V} / \mathrm{SCE}$, the cyclic voltammetry shows an oxidation peak, the current intensity of this anodic peak increases with repeated scans and a reduction peak corresponding to redox processes is also visible. However, a lower maximum oxidation current density was obtained in $\mathrm{TBAB} / \mathrm{ACN}\left(5 \mathrm{~mA} / \mathrm{cm}^{2}, 5^{\text {th }}\right.$ cycle) than in $\mathrm{LiClO}_{4} / \mathrm{ACN}(12$ $\mathrm{mA} / \mathrm{cm}^{2}$, 5th cycle), as well as a lower maximum reduction current density (only $-0.4 \mathrm{~mA} / \mathrm{cm}^{2}$ in $\mathrm{TBAB} / \mathrm{ACN}$ compared to $-1.2 \mathrm{~mA} / \mathrm{cm}^{2}$ in $\left.\mathrm{LiClO}_{4} / \mathrm{ACN}\right)$. The same general trends are observed in TS/ACN (Figure 3C) since an oxidation peak and a redox peak are also visible but with lower intensities than in $\mathrm{LiClO}_{4} / \mathrm{ACN}$ films. This tends to indicate that the polymer film is thicker and the redox processes more reversible in $\mathrm{LiClO}_{4} / \mathrm{ACN}$. The behavior observed in the presence of $\mathrm{TH}$ salt was very different (Figure 3D). Indeed, the oxidation peak is less pronounced, the reduction peak is not distinguishable, and the intensity of the oxidation peak is very low. Thus, it can be assumed that the electropolymerization of $\mathrm{Cz}$ is far more difficult in $\mathrm{TH} / \mathrm{ACN}$ than in $\mathrm{LiClO}_{4} / \mathrm{ACN}$ and TS/ACN. This is confirmed by the pictures from the samples obtained by electro-oxidation of $\mathrm{Cz}$ on FTO electrodes (Figure 2) which show that a thick and homogeneous polyCz film is obtained in $\mathrm{LiClO}_{4} / \mathrm{ACN}$ when less homogeneous films are obtained in TS/ACN and TBAB/ACN and no clearly visible film is obtained in TH/ACN.

The electrochemical activity of the polyCz films electrodeposited in the different electrolytes was also studied. To this aim, polyCz films were electrodeposited onto a $\mathrm{Pt}$ working electrode by cyclic voltammetry, then the Pt electrode with the polymer film attached was removed from the growth solution, and placed in a monomer-free solution of the solvent for post-polymerization voltammetric analysis. Since it is necessary to have enough salt to study the insertion/desinsertion of the anions in the $\mathrm{PCz}$ films, a concentration of $0.1 \mathrm{M}$ in salt was chosen.

Whatever the nature of the supporting salt, postpolymerization CVs showed a peak separation that is expected for a reversible electron transfer process (Chen and Inganas, 1996) (Figure 4). However, the oxidation and reduction peaks are more pronounced when $\mathrm{LiClO}_{4}$ was used. With this latter salt, the potential corresponding to the polyCz oxidation and reduction peaks is +1.3 and $+1.05 \mathrm{~V} / \mathrm{SCE}$, respectively, during the 1 st cycle (the potential shifted toward less anodic potentials with repeated scans). Moreover, the ratio of oxidation to reduction intensities remains constant around 2.25 with repeated scans which indicates that the doping/dedoping process happens even after a few scans. When TBAB is used as supporting electrolyte, the redox processes also take place as evidenced by the presence of the oxidation and reduction peaks at +1.35 and $+0.95 \mathrm{~V} / \mathrm{SCE}$, respectively. Moreover, these peaks are present during the repeated scans (even if the reduction peak slowly decreases) indicating doping/dedoping process. When TS is used as supporting electrolyte, the redox processes again take place as proved by the presence of the oxidation and reduction peaks at +1.3 and $+0.85 \mathrm{~V} / \mathrm{SCE}$, respectively, even if the oxidation peak is broader. The intensity of these peaks remains roughly constant with repeated scans indicating the doping/dedoping of the film by the p-toluenesulfonate anions. In the presence of TH salt, the oxidation and reduction peaks are also present but the current density is strongly lower than for the other salts indicating that the doping/dedoping process still goes on. 


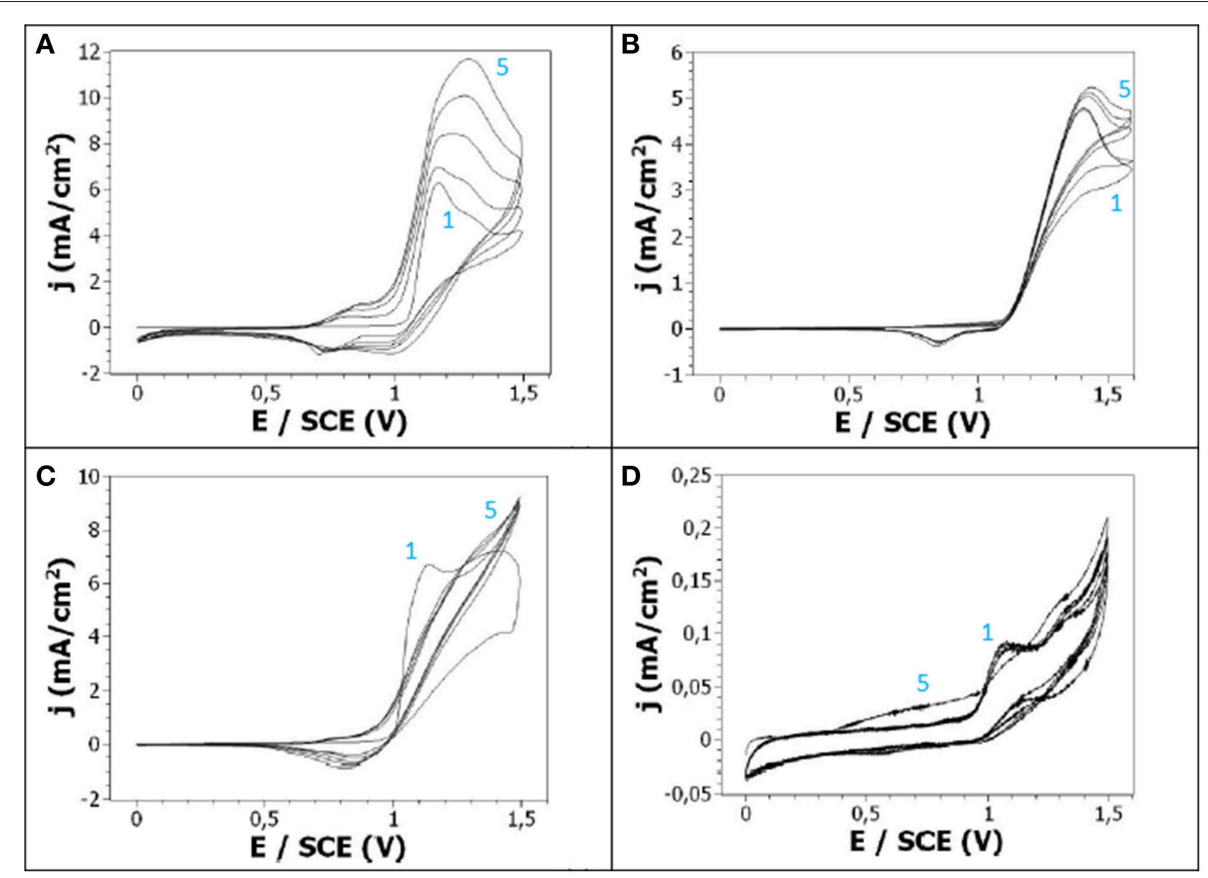

FIGURE 3 | Cyclic voltammetry of $10^{-2} \mathrm{M} \mathrm{Cz}$ in $0.1 \mathrm{M}$ (A) LiClO $4 / \mathrm{ACN}$, (B) TBAB/ACN, (C) TS/ACN, (D) TH/ACN. Scan rate: $50 \mathrm{mV} / \mathrm{s}$.
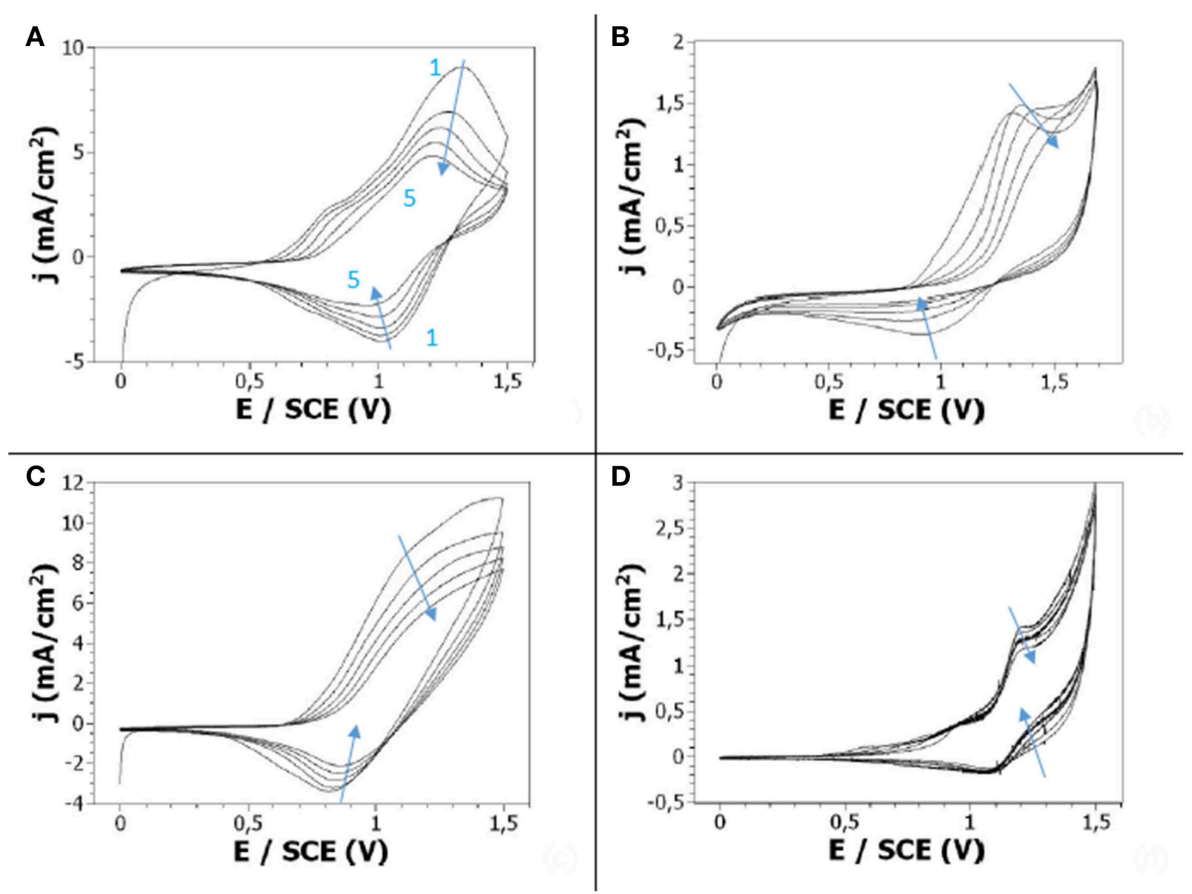

FIGURE 4 | Post-polymerization cyclic voltammetry of $10^{-2} \mathrm{M} \mathrm{Cz}$ in $0.1 \mathrm{M}$ (A) LiClO $4 / \mathrm{ACN}$, (B) TBAB/ACN, (C) TS/ACN, (D) TH/ACN. Scan rate: $50 \mathrm{mV} / \mathrm{s}$.

To conclude, the study of the electropolymerization conditions (monomer concentration, nature of the solvent and nature of the supporting salt) recommends to work in acetonitrile solutions with lithium perchlorate and a carbazole concentration of $10^{-2} \mathrm{M}$. These optimized conditions will be used in the next part of this work dedicated to the electrochemical oxidation of $\mathrm{N}$-substituted carbazole derivatives. 

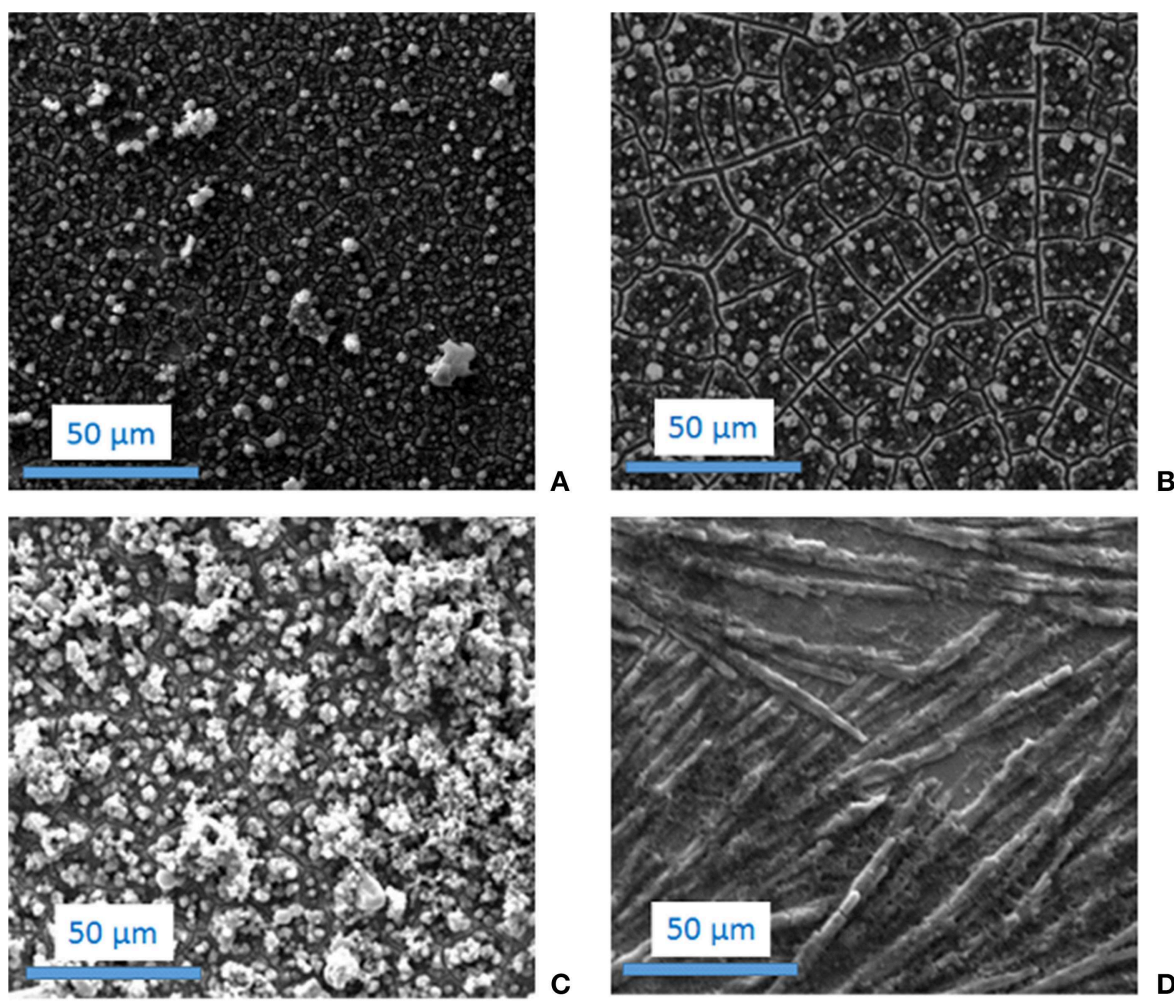

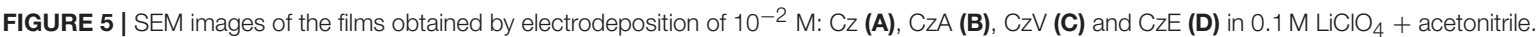

\section{Characterization of the Polycz Obtained in the Optimized Conditions}

The morphology of a polyCz film obtained from oxidation of $10^{-2} \mathrm{M} \mathrm{Cz}$ in an acetonitrile solution containing $0.1 \mathrm{M}$ $\mathrm{LiClO}_{4}$ was studied by SEM microscopy. The SEM image indicates that the overall surface of the polyCz film is homogeneous, the electrode being nearly completely covered by polymer (Figure 5A). Moreover, the film consists in small heaps electrodeposited onto the electrodes with bare domains between them. The shape of these small heaps is circular and the size of the structures varies from one to the other. Using profilometry measurements, the thickness of the polyCz films was estimated to $6-7 \mu \mathrm{m}$ and its roughness to $0.05-0.09 \mu \mathrm{m}$.

\section{N-substituted Carbazoles \\ 9-alkylcarbazoles}

In an attempt to obtain original thin solid polymer films by electrochemical oxidation of substituted carbazoles, different alkylcarbazoles were prepared by incorporation of alkyl chains at N-position. The alkyl chain length was varied to determine if this parameter has an influence on the oxidation of the modified carbazoles. The electrochemical parameters used to perform the electro-oxidation of the various $\mathrm{N}$-alkylcarbazoles were those optimized in the first part of this work: a concentration of $10^{-2} \mathrm{M}$ in monomer, $0.1 \mathrm{M} \mathrm{LiClO}_{4}$ as supporting salt and acetonitrile as solvent. Thus, the anodic oxidation of 9-ethylcarbazole (Cz1Me), 9-butylcarbazole (Cz3Me), 9-hexylcarbazole (Cz5Me), and 9octylcarbazole (Cz7Me) was performed by cyclic voltammetry at Pt electrodes, as shown in Figure 6. The onset oxidation potentials of these four alkylcarbazoles, leading to radical cations, appears at $+1.0 \mathrm{~V} / \mathrm{SCE}$. A pronounced reduction peak is also observed for all carbazole derivatives at $+0.7-0.8$ V/SCE. Both the $\mathrm{Cz}$ oxidation peak and the corresponding reduction peak are observed during the successive scans. Another peak, whose intensity is very low, can be observed around $+0.8 \mathrm{~V} / \mathrm{SCE}$. Concerning the intensity of the peaks, they are similar for all alkylcarbazoles but lower than for non-substituted carbazole (the intensity of the oxidation peak is around $6 \mathrm{~mA} / \mathrm{cm}^{2}$ for 9alkylcarbazoles instead of $12 \mathrm{~mA} / \mathrm{cm}^{2}$ for $\mathrm{Cz}$, and the reduction peak intensity was around $-0.5 \mathrm{~mA} / \mathrm{cm}^{2}$ for 9-alkylcarbazoles instead of $-1 \mathrm{~mA} / \mathrm{cm}^{2}$ for $\mathrm{Cz}$ ). Moreover, there is no clear increase in redox currents during successive cycling which means that no adherent deposit is obtained on the electrode surface. This is confirmed visually as no polymer deposit is observed (with the naked eye or with a SEM microscope) on the substrates after electrochemical oxidation.

So, it is interesting to observe that carbazole and 9alkylcarbazoles present a comparable electrochemical behavior but only carbazole leads to a polymer thin film on the working electrode. In addition, when the oxidation is performed by chronoamperometry, similar charge quantity is measured during the oxidation of $\mathrm{Cz}\left(368 \mathrm{mC} / \mathrm{cm}^{2}\right)$ and during the oxidation of Cz1Me $\left(410 \mathrm{mC} / \mathrm{cm}^{2}\right), \mathrm{Cz} 3 \mathrm{Me}\left(367 \mathrm{mC} / \mathrm{cm}^{2}\right), \mathrm{Cz} 5 \mathrm{Me}$ 

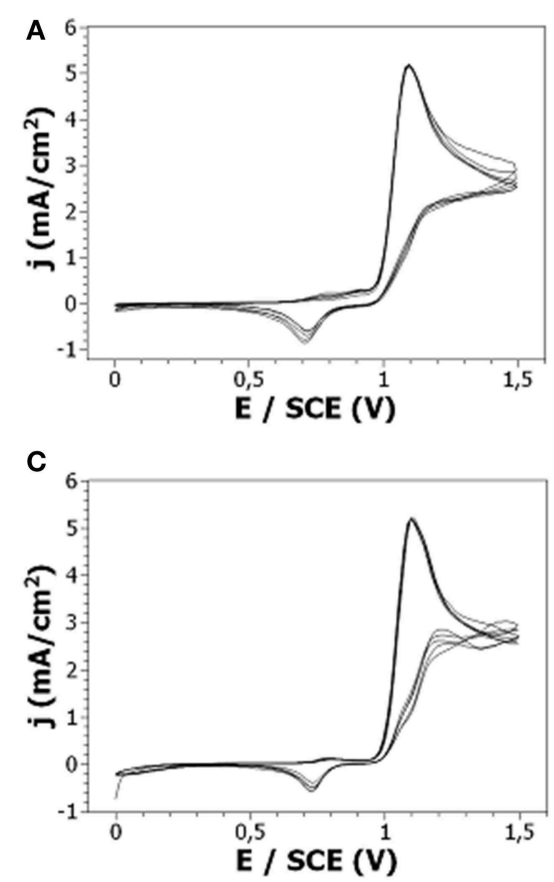

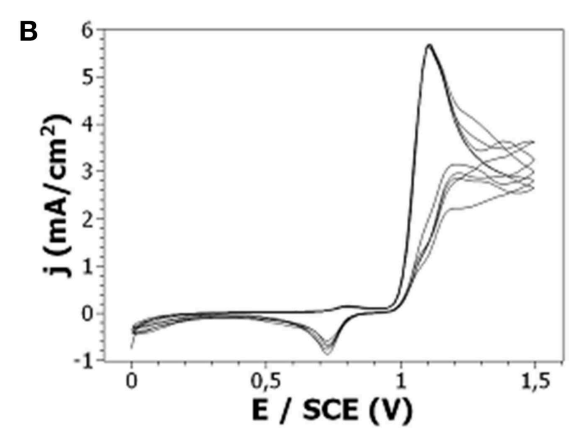

D

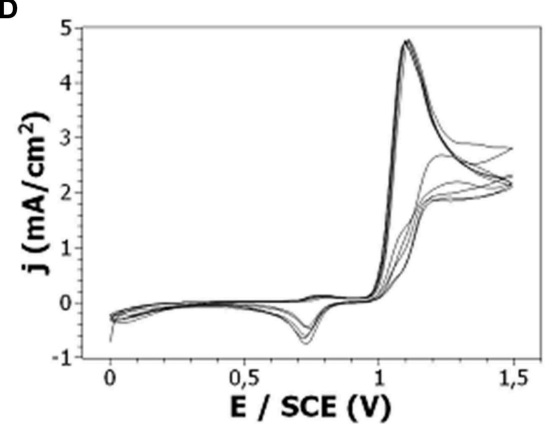

FIGURE 6 | Cyclic voltammetry at a Pt electrode of $10^{-2} \mathrm{M}$ : (A) Cz1Me, (B) Cz3Me, (C) Cz5Me, (D) Cz7Me $+0.1 \mathrm{M} \mathrm{LiClO} 4$ in ACN. Scan rate: $50 \mathrm{mV} / \mathrm{s}$.

$\left(369 \mathrm{mC} / \mathrm{cm}^{2}\right)$, and $\mathrm{Cz} 7 \mathrm{Me}\left(376 \mathrm{mC} / \mathrm{cm}^{2}\right)$ indicating that the oxidation of these species takes place without particular difficulty for all of these monomers. In the review from Kapron and Lapkowski (2015) and in the pioneer works from Ambrose and Nelson (1968) dedicated to the electrochemistry of carbazoles, it is explained that the oxidation of $\mathrm{Cz}$ leads to the formation of the cation radical in a one electron process. As the cation radical is not stable, it tends to couple with another cation radical or a parent molecule (a loss of two protons accompanies this coupling) to form a more stable bicarbazyl (which can be either 3,3'-bicarbazyl, the main product, or 9,9'-bicarbazyl, the minor product). Then, the oxidation of the oligomers takes place (at a lower potential than the oxidation of the monomers) and the electropolymerization of $\mathrm{Cz}$ occurs. On the contrary, when the nitrogen atom is blocked by a substituent, the oxidation mainly leads to dimers but not to polymers. From our point of view, this difference of behavior between $\mathrm{Cz}$ and these substituted carbazoles may be due to the difference of stability of the cation radicals obtained by electro-oxidation of $\mathrm{Cz}$ and 9-alkylcarbazoles and their dimers. To validate our assumption, we performed fast electrochemistry experiments (Figure 7) since fast electrochemistry on such diffusive systems may be interesting in terms of kinetic and thermodynamic parameters extraction (e.g., redox standard potential, heterogeneous, and dimerization rate constants) as well as for mechanisms investigation (since it could give information about the reactivity of radical cations and dimers).

For 9-ethylcarbazole, signal reversibility was reached for scan rates above $50 \mathrm{~V} / \mathrm{s}$. The oxidation peak present at +1.25 $\mathrm{V} / \mathrm{Ag} / \mathrm{AgCl}$ is due to well-known monomer oxidation into radical cation which couples with another radical cation (dimerization) as it is unstable. This dimerization is accompanied by the loss of two protons. The scan rate being very fast, a non-negligible part of radical cations is reduced before total dimerization which leads to the small reduction peak. Electrochemical simulation enabled to estimate a dimerization rate constant of about $(4.25 \pm 0.75) \times$ $10^{5} \mathrm{M}^{-1} . \mathrm{s}^{-1}$.

For 9-substituted carbazole with longer alkyl chains (i.e., 4, 6 , and 8 carbons), electrochemical behavior is more complex. Indeed, oxidation peak is wider than expected and most importantly, two reduction peaks are observed at high scan rates $(100 \mathrm{~V} / \mathrm{s})$. As previously described, electrochemical oxidation of 9-substituted carbazoles has been studied by Ambrose et al. at classical scan rates (i.e., a few hundreds of $\mathrm{mV} / \mathrm{s}$ ) leading to the mechanism previously described. Thus, the oxidation peak is due to classical oxidation/dimerization of substituted monomers. The reason that the peak is more important than the one expected for one-electron process is due to the fact that the obtained dimer is then oxidized into a radical cation dimer which is relatively stable. When shifting to reduction, the first peak shows the reduction of remaining radical cations (i.e., the ones which don't dimerize) into starting monomers. Dimerization rate constants are evaluated through this peak. The second peak is for reduction of radical cation dimer into neutral dimer. Thermodynamic and kinetic parameters extracted from electrochemical simulations are presented in Table 1. It is interesting to note that dimerization rate constant is very similar for 9- ethyl, butyl and hexyl carbazole as it keeps between $4.10^{5}$ and $5.10^{5} \mathrm{M}^{-1} . \mathrm{s}^{-1}$ regardless of chain length. However, for 9-octyl carbazole the dimerization rate constant is more 

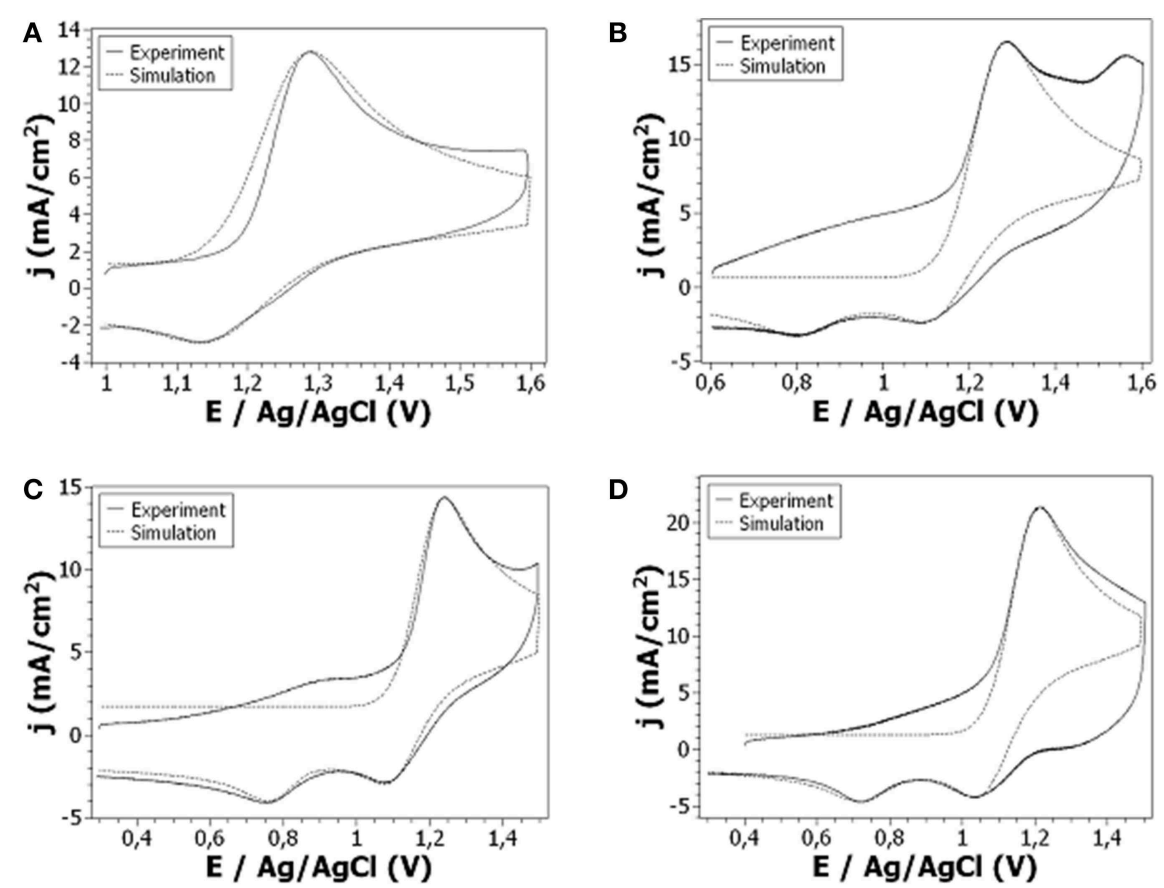

FIGURE 7 | Cyclic voltammetry at a Pt electrode of $10^{-2} \mathrm{M}$ : (A) Cz1Me, (B) Cz3Me, (C) Cz5Me, (D) Cz7Me + $0.1 \mathrm{M}$ LiClO 4 in ACN. Scan rate: 100 V/s.

TABLE 1 | Formal potential $\left(\mathrm{E}^{\circ}\right)$, heterogeneous rate constant $\left(\mathrm{k}_{\mathrm{S}}\right)$ and dimerization rate $\left(\mathrm{k}_{\mathrm{dim}}\right)$ of $\mathrm{Cz1} \mathrm{Me}, \mathrm{Cz3Me}$, Cz5Me, and $\mathrm{Cz7}$ Me deduced from fast electrochemistry experiments and corresponding simulations.

\begin{tabular}{|c|c|c|c|c|}
\hline & & $\mathrm{E}^{\circ}(\mathrm{V} / \mathrm{AgCl} / \mathrm{Ag})$ & $\mathrm{k}_{\mathrm{s}}(\mathrm{cm} / \mathrm{s})$ & $\mathrm{k}_{\mathrm{dim}}\left(\mathrm{mol}^{-1}\right.$.L.s $\left.\mathrm{s}^{-1}\right)$ \\
\hline \multirow[t]{2}{*}{ Cz1Me } & $\mathrm{Cz} 1 \mathrm{Me}^{+\circ}+\mathrm{e}^{-} \rightleftharpoons \mathrm{Cz} 1 \mathrm{Me}$ & 1.21 & $0.055 \pm 0.005$ & l \\
\hline & $2 \mathrm{Cz} 1 \mathrm{Me}^{+\circ} \rightarrow$ Dimer & / & / & $(4.25 \pm 0.75) .10^{5}$ \\
\hline & $2 \mathrm{Cz} 3 \mathrm{Me}^{+\circ} \rightarrow$ Dimer & I & / & $(4.25 \pm 0.55) .10^{5}$ \\
\hline & Dimer $^{+\circ}+\mathrm{e}^{-} \rightleftharpoons$ Dimer & 0.96 & 0.01 & l \\
\hline Cz5Me & Dimer $^{+\circ}+\mathrm{e}^{-} \rightleftharpoons$ Dimer & $0.83 \pm 0.01$ & $0.07 \pm 0.02$ & 1 \\
\hline \multirow[t]{3}{*}{$\mathrm{Cz} 7 \mathrm{Me}$} & $\mathrm{Cz} 7 \mathrm{Me}^{+\circ}+\mathrm{e}^{-} \rightleftharpoons \mathrm{Cz} 7 \mathrm{Me}$ & $1.11 \pm 0.02$ & $0.085 \pm 0.005$ & 1 \\
\hline & $2 \mathrm{Cz} 7 \mathrm{Me}^{+\circ} \rightarrow$ Dimer & / & 1 & $(2.0 \pm 0.5) .10^{5}$ \\
\hline & Dimer $^{+\circ}+e^{-} \rightleftharpoons$ Dimer & $0.815 \pm 0.005$ & 0.03 & I \\
\hline
\end{tabular}

than twice smaller probably due to steric effects beginning to take place. Moreover, there is a tight relation between carbon chain length and redox standard potential of monomer/radical cation couples. Indeed, redox potential decreases with chain length meaning that the more the carbon chain is long, the more the substituted monomer is easily oxidized. Heterogeneous rate constant $\left(\mathrm{k}_{\mathrm{s}}\right)$ also follows this trend as it increases with chain length (except for 9-hexyl and octyl carbazole for which it stays the same). This increase in $\mathrm{k}_{\mathrm{s}}$ means a faster electron transfer and therefore an easier oxidation process.

The good stability of radical cation dimers from 9alkyl substituted carbazoles can be an explanation for their non-deposition as the oxidized dimer does not polymerize very fast leading to short oligomer chains easily solubilized into the solution.

\section{Other N-substituted Carbazoles}

The oxidation of $10^{-2} \mathrm{M} \mathrm{CzA}$ and $\mathrm{CzE}$ was performed in $0.1 \mathrm{M}$ $\mathrm{LiClO}_{4}$ in acetonitrile at $\mathrm{Pt}$ electrodes. The onset oxidation potential of both carbazole derivatives is located at +1.1 V/SCE (Figures 8A-C). After the first cycle, both CzA and $\mathrm{CzE}$ oxidation potential peak intensity increases very slightly and the oxidation potential shifts toward slightly higher values. A reduction peak can also be observed at +0.8-0.9 V/SCE during the cathodic scan. A difference between the CVs of the 2 carbazole derivatives was the broadness of the oxidation 

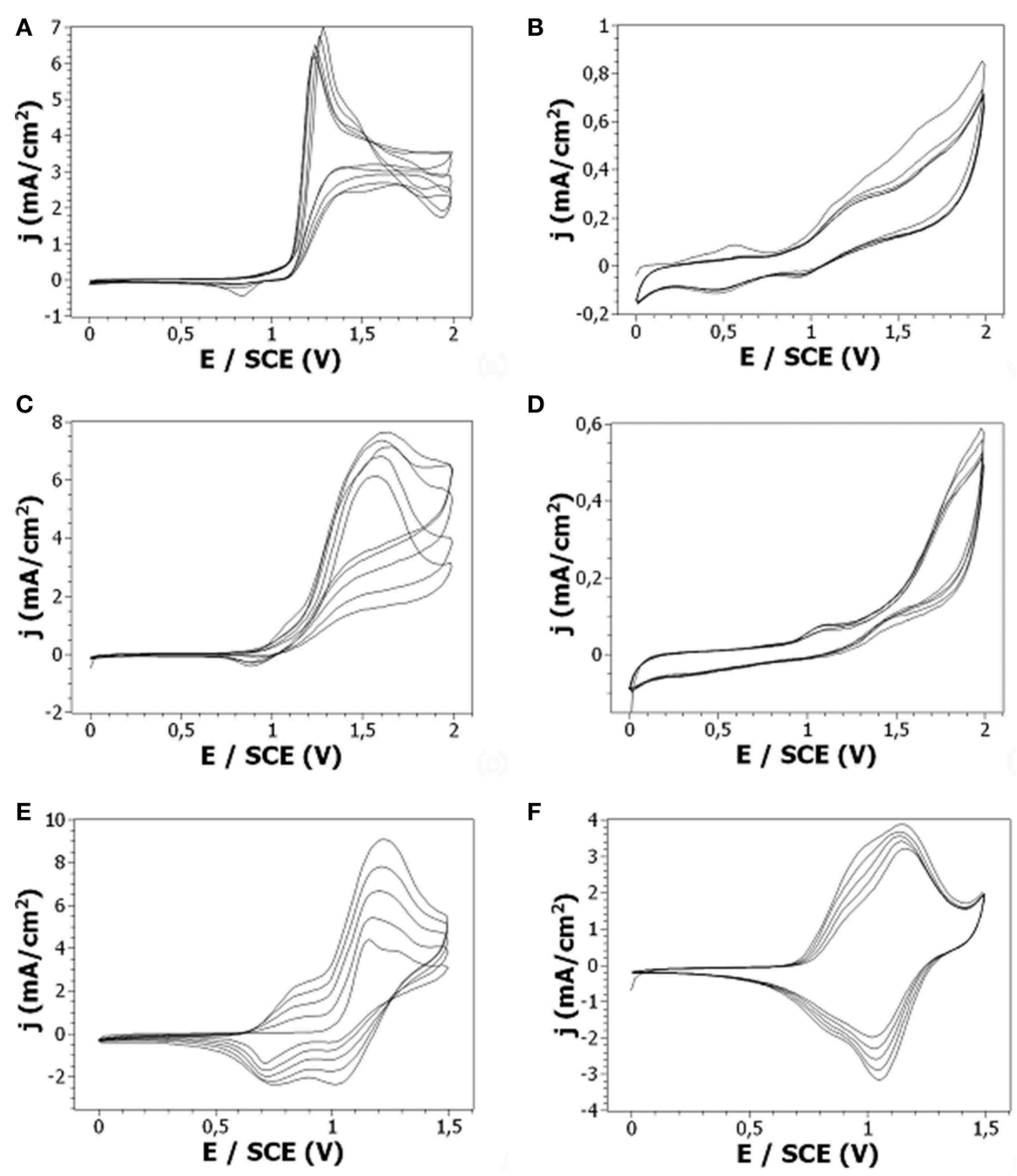

FIGURE 8 | CV (A,C,E) and post-polymerization CV (B,D,F) at a Pt electrode of $10^{-2}$ M: (A,B) CzE, (C,D) CzA, (E-F) CzV + 0.1 M LiClO 4 in ACN. Scan rate: 50 $\mathrm{mV} / \mathrm{s}$.

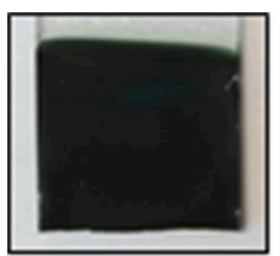

Cz

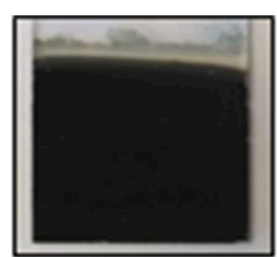

C2V

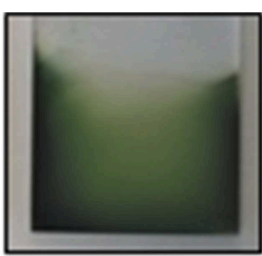

CzA

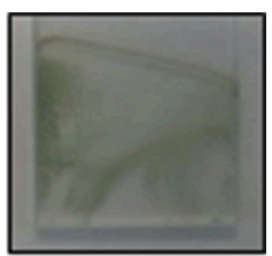

CzE

FIGURE 9 | Photographs of samples obtained by oxidation of $10^{-2} \mathrm{M} \mathrm{Cz}, \mathrm{CzV}, \mathrm{CzA}$, and $\mathrm{CzE}$ in an acetonitrile solution (containing $0.1 \mathrm{M}$ LiClO 4 ).

peak. Indeed, CzA leads to a broader oxidation peak than $\mathrm{CzE}$ indicating that more CzA monomers are oxidized (since the oxidation of CzA takes place over a wider potential range and with a comparable oxidation peak intensity). Moreover, looking at these 2 samples at the end of the potentiodynamic electrodeposition, it is clear than the oxidation of $\mathrm{CzA}$ results in a uniform green-colored film, when the oxidation of $\mathrm{CzE}$ results in a thin poor-quality film since only some parts of the substrate are coated (Figure 9).

Concerning $\mathrm{CzV}$, the potentiodynamic electrodeposition on platinum displays an oxidation onset at $+1.0 \mathrm{~V} / \mathrm{SCE}$ (Figure 8E). Successive scans exhibit increasing anodic current peaks with corresponding cathodic peaks. More precisely, during the 1st scan, only an anodic peak can be observed, at $+1.3 \mathrm{~V} / \mathrm{SCE}$, 
which corresponds to the oxidation of the monomer into cation radicals leading to dimers. During the next scans, another peak is visible at $+0.8 \mathrm{~V} / \mathrm{SCE}$ which is due to the oxidation of oligomers. Hence, the anodic scans correspond to oxidation of the carbazole unit to give the carbazyl radical cation, which, upon cathodic scan, pairs up with another carbazyl moiety adjacent to it to form a dimer. Subsequent current increase (both anodic and cathodic) explains that the process is iterated to give dimers, trimers, oligomers on the working electrode. In addition, it can be noticed that when dimerization occurs, $\mathrm{H}^{+}$ions split-off and provoke the polymerization of $\mathrm{CzV}$ through its vinyl group. However, if the oxidation of the vinyl groups happens, there is no distinguishable additional oxidation peak. Indeed, the oxidation peak centered at +1.2 $\mathrm{V} / \mathrm{SCE}$ is too broad to discriminate the oxidation of the nitrogen atom of $\mathrm{CzV}$ monomers and the oxidation of its vinyl group. Moreover, the attack of the protons on the vinyl group of the growing polymer causes cross-linking of the film through the vinyl groups as previously evidenced by ReynaGonzalez using SEM microscopy and FTIR spectroscopy (ReynaGonzalez et al., 2006), thus leading to a compact polymer film. Indeed, at the end of the potentiodynamic electrodeposition, a thick green polymer film is observed at the electrode surface (Figure 9) which appeared comparable to the polyCz film previously electrodeposited.

The determination of thermodynamic and kinetic parameters was possible by fast electrochemistry only for 9-alkylcarbazoles since oxidation of carbazole and its other derivatives $(\mathrm{Cz}, \mathrm{CzA}$, $\mathrm{CzE}$, and $\mathrm{CzV}$ ) leads to cation radicals whose stability was not high enough to allow thermodynamic and kinetic parameters extraction. Indeed, under our experimental conditions, it is not possible to estimate dimerization rate constants higher than $10^{7}$ $\mathrm{M}^{-1} \cdot \mathrm{s}^{-1}$ as cation radicals dimerize too fast, followed by rapid polymerization process leading to a thin conducting polymer film on the microelectrode surface which prevents from any further investigation.

The electrochemical activity of the films electrodeposited by oxidation of $\mathrm{CzE}, \mathrm{CzA}$, and $\mathrm{CzV}$ in $\mathrm{LiClO}_{4}$ in acetonitrile was then studied at a $\mathrm{Pt}$ electrode by cyclic voltammetry in a monomer-free solution of the solvent. Thus, the postpolymerization $\mathrm{CV}$ of $\mathrm{CzV}$ shows a peak separation (Figure $8 \mathrm{~F}$ ) that is expected for a reversible electron transfer process and which was previously observed for polyCz (Figure 4A). More precisely, the potential of the oxidation peak, corresponding to the perchlorate anions insertion into the poly(9-vinylcarbazole) film, is located at $+1.2 \mathrm{~V} / \mathrm{SCE}$, when the reduction peak, corresponding to the ejection of perchlorate anions from the film, is located at $+1.05 \mathrm{~V} / \mathrm{SCE}$. Moreover, the ratio of oxidation to reduction intensities remains constant around 1.3-1.5 with repeated scans indicating that the doping/dedoping process occurs even after a few scans. On the contrary, the postpolymerization CVs of CzA and CzE don't show a well-defined peak separation (Figures 8B,D) even if it is noticeable than CzA leads to more distinguishable oxidation and reduction peaks than $\mathrm{CzE}$ (Figure 8F). In addition the current densities measured are far lower than those obtained during the postpolymerization of $\mathrm{CzV}$. Thus, it seems that the films obtained by oxidation of $\mathrm{CzE}$ and $\mathrm{CzA}$ are weakly electroactive which means that the doping and dedoping of these films happens with difficulty.

The morphology of the films obtained by oxidation of these carbazole derivatives was then studied by SEM. The structure of the polyCzA is comparable to the one of $\mathrm{PCz}$ since it also consists in small circular heaps covering the whole surface of the substrate (Figure 5B). It can just be remarked that the size of the bare domains separating the globules is higher for polyCzA than for polyCz. The polyCzV films also contains globules but these globules agglomerate to form big aggregates composed of tens of globules [the same structure was already observed for polyCzV by Reyna-Gonzalez et al. (2006)]. It seems that the amount of polymer substance on the substrate is higher for polyCzV than for the other polymer materials (Figure 5C). Finally, the polyCzE film presents a very different and less uniform structure which doesn't consist in globules but in more extended shapes (Figure 5D). Using profilometry measurements, the thickness of the polyCzV films was estimated to $10-11 \mu \mathrm{m}$ and its roughness to $0.4-0.6 \mu \mathrm{m}$ indicating that these polymer films are thicker and have a higher roughness than polyCz films. On the contrary, polyCzA and polyCzE films are very thin $(<1 \mu \mathrm{m})$ and have a roughness which is difficult to estimate since these electrodeposited films are not uniform.

\section{CONCLUSION}

The electropolymerization of carbazole was performed and the electrodeposition conditions were optimized. Thus, it was evidenced that it is better to perform the electro-oxidation of carbazole in acetonitrile solutions with perchlorate lithium and at a carbazole concentration of $10^{-2} \mathrm{M}$. Resulting polyCz film was thick, green-colored, and consists in globules covering the whole substrate and exhibiting a high electrochemical activity.

After organic synthesis of 9-alkylcarbazoles with various alkyl chain lengths, the same electrodeposition conditions were used in order to perform their electropolymerization. However, no deposit was observed at the electrode surface. Fast electrochemistry experiments allowed us to demonstrate that the high stability of resulting radical cation dimers is the explanation for their non-deposition as the oxidized dimers don't polymerize very fast leading to short oligomer chains.

On the contrary, for other carbazole derivatives, obtained by chemical grafting of acid, ester or vinyl groups on the $\mathrm{N}$ position of carbazole, cation radicals are much less stable and polymerization process is more efficient leading to solid polymer films. The quality of these electrodeposited films varies from one compound to the other. Thus, the oxidation of $\mathrm{Cz}, \mathrm{CzA}$, and $\mathrm{CzV}$ leads to the formation of thick, uniform, green-colored films which are electroactive and present globules on the surface when the oxidation of $\mathrm{CzE}$ leads to a non-uniform film.

The carbazole N-substitution by various groups affects the radical cation stability, even if the functional group is not conjugated to the aromatic moiety. As a consequence, the quality of electrodeposited thin films is dependent of the N-substitution functional group.

The possible applications of the substituted polycarbazole films prepared in this work mainly concern the elaboration of chemical (bio)sensors and electrochromic devices. Indeed, the 
fabrication of chemiresistors based on these polymer films can be envisaged since it is possible to tune their conductivity. Similarly, the presence of grafted ester and carboxyl groups open the way to the use of polymer films for anchoring biological molecules for biomedical applications. Also, the preparation of electrochromic devices can be envisaged since the color of the polymer films reversibly switches from white to green when changing the potential applied to the polymer-modified electrode.

\section{DATA AVAILABILITY}

The datasets generated for this study are available on request to the corresponding author.

\section{REFERENCES}

Akiyama, T., Fukuyama, T., Sugawa, K., Yoneda, H., and Yamada, S. (2009). Photocurrent generation properties of electrochemically polymerized terthiophene-linked fullerene film. Synth. Met. 159, 965-968. doi: 10.1016/j.synthmet.2009.02.019

Ambrose, J. F., Carpenter, L. L., and Nelson, R. F. (1975). Electrochemical and spectroscopic properties of cation radicals (III. Reaction pathways of carbazolium radical ions). J Electrochem. Soc. 122, 876-893. doi: $10.1149 / 1.2134365$

Ambrose, J. F., and Nelson, R. F. (1968). Anodic oxidation pathways of carbazoles (Carbazole, I., and N-substituted derivatives). J Electrochem. Soc. 115,1159-1163. doi: 10.1149/1.2410929

Atobe, M., Tsuji, H., Asami, R., and Fuchigami, T. (2006). A study on doping-undoping properties of polypyrrole films electropolymerized under ultrasonication electrochemical synthesis and engineering. J. Electrochem. Soc. 153, D10-D13. doi: 10.1149/1.2130664

Bryan, A. M., Santino, L. M., Lu, Y., Acharya, S., and D’Arcy, J. M. (2016). Conducting polymers for pseudocapacitive energy storage. Chem. Mater. 28, 5989-5998. doi: 10.1021/acs.chemmater.6b01762

Cai, M., Xiao, T., Chen, Y., Hellerich, E., Liu, R., Shinar, R., et al. (2011). Effect of molecular weight on the efficiency of poly(N-vinylcarbazole)-based polymer light-emitting diodes. Appl. Phys. Lett. 99:203302. doi: 10.1063/1.3659467

Cai, S., Wen, H., Wang, S., Niu, H., Wang, C., Jiang, X., et al. (2017). Electrochromic polymers electrochemically polymerized from 2, 5dithienylpyrrole (DTP) with different triarylamine units: synthesis, characterization and opto electrochemical properties. Electrochim. Acta 228, 332-342. doi: 10.1016/j.electacta.2017.01.071

Chen, X., and Inganas, O. (1996). Three-step redox in polythiophenes: evidence from electrochemistry at an ultramicroelectrode. J. Phys. Chem. 100, 15202-15206. doi: 10.1021/jp.9601779

Chevrot, C., Ngbilo, E., Kham, K., and Sadki, S. (1996). Optical and electronic properties of undoped and doped poly(N-alkylcarbazole) thin layers. Synth. Met. 81, 201-204. doi: 10.1016/S0379-6779(96)03752-6

Chmielewski, M., Grzeszczuk, M., Kalenik, J., and Kpas-Suwara, A. (2010). Evaluation of the potential dependence of 2D-3D growth rates and structures of polypyrrole films in aqueous solutions of hexafluorates. J. Electroanal. Chem. 647 169-180. doi: 10.1016/j.jelechem.2010.06.006

Conn, M. M., Deslongchamps, G., de Mendoza, J., and Rebek Jr., J. (1993). Convergent functional groups. 13. High-affinity complexation of adenosine derivatives within induced binding pockets. J. Am. Chem. Soc. 115, 3548-3557. doi: $10.1021 /$ ja00062a020

Darmanin, T., and Guittard, F. (2014). Wettability of conducting polymers: from superhydrophilicity to superoleohydrophobicity. Prog. Polym. Sci. 39, 656-682. doi: 10.1016/j.progpolymsci.2013.10.003

Fonseca, S. M., Moreira, T., Parola, A. J., Pinheiro, C., and Laia, C. A. T. (2017). PEDOT electrodeposition on oriented mesoporous silica templates for electrochromic devices. Sol. Energy Mater. Sol. Cells 159, 94-101. doi: 10.1016/j.solmat.2016.09.002

\section{AUTHOR CONTRIBUTIONS}

EC performed the organic synthesis, CS, SL, CM, and AE performed the electrochemical experiments. BL performed SEM microscopy. All contributed to discussions and writing of the paper.

\section{SUPPLEMENTARY MATERIAL}

The Supplementary Material for this article can be found online at: https://www.frontiersin.org/articles/10.3389/fmats. 2019.00131/full\#supplementary-material

Figure $\mathbf{S 1} \mid{ }^{1} \mathrm{H}$ and ${ }^{13} \mathrm{C}$ NMR spectra of synthesized carbazole monomers.

Grigalevicius, S., Zhang, B. H., Xie, Z. Y., Forster, M., and Scherf, U. (2011). Polycarbazole-based networks made by photo-crosslinking for hole transporting layers of OLED devices. Org. Electron. 12, 2253-2257. doi: 10.1016/j.orgel.2011.08.018

Hsiao, S. H., and Lin, S. W. (2016). Electrochemical synthesis of electrochromic polycarbazole films from N-phenyl-3,6-bis(N-carbazolyl)carbazoles. Polym. Chem. 7, 198-211. doi: 10.1039/C5PY01407G

Hu, B., Lv, X. J., Sun, J. W., Bian, G. F., Ouyang, M., Fu, Z. Y., et al. (2013). Effects on the electrochemical and electrochromic properties of 3,6 linked polycarbazole derivative by the introduction of different acceptor groups and copolymerization. Org. Electron. 14, 1521-1530. doi: 10.1016/j.orgel.2013.03.024

Huang, Z. H., Hu, S. C., Zhang, N., Chen, X. L., Chen, D., Jin, Q., et al. (2012). Effect of volume ratio of acetonitrile to water on the morphology and property of polypyrrole prepared by chemical oxidation method. Polym. Eng. Sci. 52, 1600-1605. doi: 10.1002/pen.23101

Joshi, N., Saxena, V., Singh, A., Koiry, S. P., Debnath, A. K., Chehimi, M. M., et al. (2014). Flexible $\mathrm{H}_{2} \mathrm{~S}$ sensor based on gold modified polycarbazole films. Sens. Actuators B 200, 227-234. doi: 10.1016/j.snb.2014.04.041

Kapron, K. and Lapkowski, M. (2015). Carbazole electrochemistry: a short review. Sol. St. Electrochem. 19, 2601-2610. doi: 10.1007/s10008-015-2973-x

Kausar, A. (2017). Overview on conducting polymer in energy storage and energy conversion. J. Macromol. Sci. A. 54, 640-653. doi: 10.1080/10601325.2017.1317210

Lee, Y., Zhou, H., and Lee, T. W. (2018). One-dimensional conjugated polymer nanomaterials for flexible and stretchable electronics. J. Mater. Chem. 14, 3538-3550. doi: 10.1039/C7TC05927B

Li, A. Y., Li, Y. Y., Cai, W. Z., Zhou, G. J., Chen, Z., Wu, H. B., et al. (2010). Realization of highly efficient white polymer light-emitting devices via interfacial energy transfer from poly(N-vinylcarbazole). Org. Electron. 11, 529-534. doi: 10.1016/j.orgel.2009.12.008

Mali, S. P., Gosavi, S. A., Inamdar, A. S., Chougale, U. M., and Fulari, V. J. (2015). Synthesis and characterizations of chemically and electrochemically polymerized polyaniline thin films for energy storage. Adv. Sci. Lett. 21, 2534-2538. doi: 10.1166/asl.2015.6414

Ouyang, J., Chu, C. W., Chen, F. C., Xu, Q., and Yang, Y. (2005). Highconductivity poly(3,4-ethylenedioxythiophene):poly(styrene sulfonate) film and its application in polymer optoelectronic devices. Adv. Funct. Mater. 15, 203-208. doi: 10.1002/adfm.200400016

Papez, V., and Josowicz, M. (1994). Electrochemical preparation and study of poly(N-vinylcarbazole) as a sensing layer for propylamine vapor. J. Electroanal. Chem. 365, 139-150. doi: 10.1016/0022-0728(93)02979-R

Park, Y. H., Kim, S. J., and Lee, J. Y. (2003). Preparation and characterization of electroconductive polypyrrole copolymer Langmuir-Blodgett films. Thin Solid Films 425, 233-238. doi: 10.1016/S0040-6090(02)01123-9

Patois, T., Lakard, B., Martin, N., and Fievet, P. (2010). Effect of various parameters on the conductivity of free standing electrosynthesized polypyrrole films. Synth. Met. 160, 2180-2185. doi: 10.1016/j.synthmet. 2010.08.005 
Patois, T., Lakard, B., Monney, S., Roizard, X., and Fievet, P. (2011). Characterization of the surface properties of polypyrrole films. Influence of the electrodeposition parameters. Synth. Met. 161, 2498-2505. doi: 10.1016/j.synthmet.2011.10.003

Peng, X. Y., Luan, F., Liu, X. X., Diamond, D., and Lau, K. T. (2009). pHcontrolled morphological structure of polyaniline during electrochemical deposition. Electrochim. Acta 54, 6172-6177. doi: 10.1016/j.electacta. 2009.05.075

Petrov, R. R., Knight, L., Chen, S. R., Wager-Miller, J., Mc Daniel, S. W., Diaz, F., et al. (2013). Mastering tricyclic ring systems for desirable functional cannabinoid activity. Eur. J. Med. Chem. 69, 881-907. doi: 10.1016/j.ejmech.2013.09.038

Reyna-Gonzalez, J. M., Aguilar-Martinez, M., Bautista-Martinez, J. A., Rivera, E., Gonzalez, I., and Roquero, P. (2006). Influence of the acidity level on the electropolymerization of $\mathrm{N}$-vinylcarbazole: electrochemical study and characterization of poly(3,6-N-vinylcarbazole). Polymer 47, 6664-6672. doi: 10.1016/j.polymer.2006.07.023

Reyna-González, J. M., Roquero, P., and E., Rivera E (2009). A comparative investigation between poly(N-vinylcarbazole) and poly(3,6Nvinylcarbazole): spectroscopy, conductivity, thermal and optical properties. Des. Monomers Polym. 12, 233-245. doi: 10.1163/156855509X4 36058

Sarac, A. S., Ates, M., and Parlak, E. A. (2006). Electrolyte and solvent effects of electrocoated polycarbazole thin films on carbon fiber microelectrodes. J. Appl. Electrochem. 36, 889-898. doi: 10.1007/s10800006-9145-8

Sarac, A. S., and Bardavit, Y. (2004). N-vinylcarbazole-styrene free radical polymerization and electrochemical and chemical oxidation of $\mathrm{P}(\mathrm{NVCz}-$ co-sty) and $\mathrm{P}(\mathrm{NVCz}-\mathrm{co}-\mathrm{AN})$ : cyclic voltammetric, spectroscopic (FTIR) and conductometric study. Int. J. Polym. Mater. 53, 185-200. doi: 10.1080/00914030490267609

Saraswathi, R., Gerard, M., and Malhotra, B. D. (1999). Characteristics of aqueous polycarbazole batteries. J. Appl. Polym. Sci. 74, 145--50. doi: 10.1002/ (SICI) 1097-4628(19991003)74:1\%3C145::AID-APP18\%3E3.0.CO;2-C

Sathiyan, G., and Sakthivel, P. (1993). A multibranched carbazole linked triazine based fluorescent molecule for the selective detection of picric acid. RSC Adv. 6, 106705-106715. doi: 10.1039/C6RA22632A

Savagatrup, S., Printz, A. D., O’Connor, T. F., Zaretski, A. V., and Lipomi, D. J. (2014). Molecularly stretchable electronics. Chem. Mater. 26, 3028-3041. doi: $10.1021 / \mathrm{cm} 501021 \mathrm{v}$

Shirakawa, H., Louis, E. J., MacDiarmid, A. G., Chiang, C. K., and Heeger, A. J. (1977). Synthesis of electrically conducting organic polymers: halogen derivatives of polyacetylene, $(\mathrm{CH})_{\mathrm{x}}$. J. Chem. Soc. Chem. Commun. 1977, 578-580. doi: 10.1039/c39770000578

Srivastava, A., and Chakrabarti, P. (2015). An organic Schottky diode (OSD) based on a-silicon/polycarbazole contact. Synth. Met. 207, 96-101. doi: 10.1016/j.synthmet.2015.05.024

Su, P. Y., Huang, L. B., Liu, J. M., Chen, Y. F., Xiao, L. M., Kuang, D. B., et al. (2017). A multifunctional poly-N-vinylcarbazole interlayer in perovskite solar cells for high stability and efficiency: a test with new triazatruxene-based hole transporting materials. J. Mater. Chem. A 5, 1913-1918. doi: 10.1039/C6TA09314K

Vedarajan, R., Hosono, Y., and Matsumi, N. (2014). pi-Conjugated polycarbazoleboron complex as a colorimetric fluoride ion sensor. Sol. Stat. Ion. 262, 795-800 doi: 10.1016/j.ssi.2013.09.062

Viau, L., Hihn, J. Y., Lakard, S., Moutarlier, V., Flaud, V., and Lakard, B. (2014). Full characterization of polypyrrole thin films electrosynthesized in room temperature ionic liquid, water or acetonitrile. Electrochim. Acta 137, 298-310. doi: 10.1016/j.electacta.2014.05.143

Wei, Z., Xu, J., Nie, G., Du, Y., and Pu, S. (2006). Low-potential electrochemical polymerization of carbazole and its alkyl derivatives. J. Electroanal. Chem. 589, 112-119. doi: 10.1016/j.jelechem.2006.01.023

Wojcik, K., and Grzeszczuk, M. (2015). Surface morphology of thin polypyrrole films electrodeposited along aqueous electrolyte-organic liquid interface. Influence of temperature and solvent. J. Sol. State Electrochem. 19, 1293-1300. doi: $10.1007 / \mathrm{s} 10008-015-2750-\mathrm{x}$

Yaguee, J. L., Agulo, N., and Borros, S. (2008). Plasma polymerization of polypyrrole-like films on nanostructured surfaces. Plasma Proces. Polym. 5, 433-443. doi: 10.1002/ppap.200700139

Zhang, T., Wang, J., Zhou, M., Ma, L., Yin, G., Chen, G., et al. (2014). Influence of polyhedral oligomeric silsesquioxanes (POSS) on blue light-emitting materials for OLED. Tetrahedron 70, 2478-2486. doi: 10.1016/j.tet.2013.11.082

Conflict of Interest Statement: The authors declare that the research was conducted in the absence of any commercial or financial relationships that could be construed as a potential conflict of interest.

Copyright (C) 2019 Contal, Sougueh, Lakard, Et Taouil, Magnenet and Lakard. This is an open-access article distributed under the terms of the Creative Commons Attribution License (CC BY). The use, distribution or reproduction in other forums is permitted, provided the original author(s) and the copyright owner(s) are credited and that the original publication in this journal is cited, in accordance with accepted academic practice. No use, distribution or reproduction is permitted which does not comply with these terms. 